\title{
Personal Injury Compensation A Summary of the Geneva Association's Comparative Study
}

\author{
by Werner Pfennigstorf*
}

\section{Introduction}

One of the most ambitious and most time-consuming studies that the Geneva Association has sponsored so far has just been completed. The result is a book published by Lloyd's of London Press. ${ }^{1}$

The book is actually the product of the second stage of the project. A number of papers produced in a preliminary and exploratory stage, covering Germany, the Netherlands and the United Kingdom, were published in a special issue of this series two years ago, ${ }^{2}$ together with an overview of how the study was conceived, what it was expected to achieve, how it was designed to proceed, and how it compared to other current studies.

This summary, consequently, concentrates on the second stage, although some repetition is unavoidable, as it has proven unavoidable in the book. In any event, to have the full benefit of the study, anyone interested in the subject should study both the book and No. 56 of the Geneva Papers.

This summary is based mostly on this author's Introduction and General Report in the book.

One repetition which, while not unavoidable, seems most appropriate, is to mention the name of Martin Albaum. It was Martin Albaum who, as Vice President, Research of the Prudential Property and Casualty Insurance Company, wrote to the Geneva Association to propose a study of this kind. That was in the Summer of 1986, at the height of the liability insurance crisis in the United States. Martin Albaum has since retired, the crisis has passed, and liability cover is available again at competitive prices.

\footnotetext{
* Werner Pfennigstorf, Dr. jur. habil., M. C. L., is an Attorney and Consultant at Law practicing in Düdenbüttel (near Hamburg).

${ }^{1}$ Personal Injury Compensation: Sources and Procedures in Six European Countries. Edited by Werner Pfennigstorf. London: Lloyd's of London Press, 1992.

2 Comparative Liability Studies, Geneva Papers Vol. 15 No. 56 (1990).
} 
The basic problems of tort liability in the United States, however, which existed long before the crisis of 1985 and 1986, still persist, and the debate about tort reform has taken on a new dimension since the President's Council on Competitiveness, under the Chairmanship of the Vice President, has proposed a number of far-reaching changes. ${ }^{3}$

If the renewed debate, which is not limited to the United States but due do the international interdependencies of the liability insurance business necessarily extends to Europe and other parts of the world, can now benefit from the results of the Geneva Association's study, it is appropriate to acknowledge the contribution of the man who proposed the study, guided by a vision that extended beyond the unique circumstances of a single market crisis.

\section{Outline of the study}

\subsection{Purposes}

Essentially, the study seeks to contribute to a better understanding of our liability and compensation systems by showing how they work in practice and specifically, by providing information of a kind that heretofore has not been available:

First, in contrast to other studies, which focused on liability law and procedure and the awards resulting therefrom, this study includes benefits from other sources, notably social security and private first-party insurance.

Second, the study describes the rules and mechanisms by which the different sources of compensation are linked and coordinated, notably rules on loss reduction, limitation of benefits, and subrogation.

Third, the practical effects of the rules of six countries are illustrated by calculating compensation amounts for a set of uniform cases.

The results should allow policymakers both in the countries studied and elsewhere to appreciate the extent to which accident victims in different situations are actually compensated from different sources, how the different compensation regimes are coordinated, and how the costs of compensation are eventually allocated.

Those who did the study are convinced that this will contribute to a more rational discussion of proposals and possibilities to change existing systems, be it with a view to expanding the scope of compensation, to avoiding overcompensation, to promoting administrative efficiency, to making the system more equitable or more cost-effective, or to redistributing its financial burden.

\subsection{Limits}

It seems equally important to point out what this study does not intend to do:

We do not aim at supplying actuaries with reliable statistical data on which to base insurance premium calculations.

We do not offer a ready-made model for reforming or restructuring individual national systems, let alone for creating a uniform system for all countries.

We do not claim to be able to define the "right" method or amount of compensation. If the figures appearing in our reports happen to be larger for some countries than for

\footnotetext{
${ }^{3}$ Agenda for Civil Justice Reform in America: A Report from the President's Council on Competitiveness, Washington, D.C., August 1991.
} 
others, that does not mean that one amount responds more adequately to the victims' loss than the other. Such a crude comparison of figures would be totally wrong and unjustified not only because it would ignore the many economic and social factors that determine need and loss differently in each country, but most decidedly because it would reflect a fundamental misconception of the nature and aims of personal injury compensation.

On the contrary, we believe that the reports collected here show convincingly how the goal of the "right" compensation can be approached in different ways, and that each of such ways can be the right one in the context of the cultural and especially legal tradition in which it developed.

It should be evident that the amounts mentioned as results in the different reports for the model cases are not meant, and should not be used, as reliable indicators of results to be expected in similar cases in the future.

Much less can the figures mentioned in this study be a suitable basis for comparison, either among the different countries included in the study or with other countries.

The focus of this study, as explained, is on procedures and considerations applied in determining and coordinating compensation from different sources. Actual compensation always depends on the unique facts of each individual case. To the extent that figures are mentioned in this study, they cannot be more than rough indicators of the possible dimension or range of expected compensation.

The following special caveats, originally pointed out by Professor Fredericq in his report on Belgium, should be kept in mind:

(a) The amounts of liability awards and social benefits can be properly evaluated only in relation to prevailing wage levels, which vary by wide margins among the European countries. According to figures published in the "Bulletin d'Information" of the Commission of the European Communities, the relations for some of the countries included in this study are: France, 7.5 units; Belgium, 10 units; Germany, 10.5 units; Netherlands and United Kingdom, 11 units.

(b) Differences in income tax systems also have a strong impact. In countries where tax progression is steep, as in Belgium, salaries for upper-level employees tend to be much larger in comparison to countries where taxes are more moderate, such as France.

(c) Social security systems are different throughout Europe, for a variety of political reasons. Notably, some do and some do not include self-employed persons, and benefit levels differ considerably.

\subsection{Other studies}

In the time since we started this study, the level of compensation for accidental injuries in different European countries has been the subject of other comparative studies. ${ }^{4}$ We are also aware of the work that has been devoted, under the auspices of the Commission of the $\mathrm{EC}$, to the determination of personal injury, aimed at developing uniform standards for automobile accident compensation. ${ }^{5}$

${ }^{4}$ D. McIntosh and M. Holmes, Personal Injury Awards in EC Countries: An Industry Report, London: Lloyd's of London Press, 1991; P. Szöllösy, Recent Trends in the Standard of Compensation for Personal Injury in a European Context, in Scandinavian Insurance Quarterly, 1991, No. 3, pp. 191-222.

5 A. Dessertine, l'Evaluation du préjudice corporel dans les pays de la C. E. E., Paris, : Litec, 1990. 
We have studied these publications and have been encouraged by finding that the subject is not easily exhausted but can be studied with great benefit from different angles. We have concluded that our own effort does not duplicate any of the other studies but represents a unique and independent contribution, notably by exploring in detail the interaction of the different sources of compensation. ${ }^{6}$

\subsection{The second stage}

For the second stage of the project, the scope was extended by adding three more countries (Belgium, France and Sweden), and a set of 15 accident/injury situations was developed as a uniform basis for the national reports.

The selection of countries was in part influenced by the availability of appropriately qualified reporters. Eventually, a group of experts bearing impressive credentials was assembled:

for Belgium:

Simon Fredericq, Professor Emeritus, Rijksuniversiteit Gent, Honorary President, International Association for Insurance Law (AIDA), Gent, and

Kristiaan Bernauw, Assistant, Rijksuniversiteit Gent;

for France :

Claude Delpoux, Directeur Responsabilité Civile, Assemblée Plénière des Sociétés d'Assurances Dommages (A.P.S. A.D.), Paris, and

André Tomadini, Président, Commission des Sinistres Corporels, Assemblée Plénière des Sociétés d'Assurances Dommages (A.P.S. A. D.), Paris ;

for the Netherlands:

Dr. F. Theo Kremer, Legal Advisor, Nationale Nederlanden, Den Haag,

Robert A. Salomons, recently retired from the position of Legal Advisor, Delta-Lloyd Insurance Company, Zaandam, and

John H. Wansink, Professor of Law, Erasmus Universiteit Rotterdam;

for Sweden:

Dr. Carl Oldertz, recently retired from the position of Divisional Director, Skandia Insurance Group, Stockholm ;

for the United Kingdom:

Kenneth S. Cannar, B.Sc., F. C. I. I., Barrister, Goudhurst (Kent), and

Frederick W. Collins, LL. B., A.C. I. I., recently retired from the position of Claims Manager, Eagle Star Insurance Company, also Member of the Legal Aid Board, Woking (Surrey).

The author of this Summary served as coordinator of the study and also as national reporter for Germany.

In preparing their national reports, the reporters relied on experienced insurance claims practitioners either to perform the calculations or at least to review them for conformity with prevailing practice. This help is gratefully acknowledged.

${ }^{6}$ A parallel study, exploring alternative compensation sources and their interaction on a broader scale but without case illustrations, under the auspices of the Insurance Research Council, was completed a short time ago: Werner Pfennigstorf with Donald G. Gifford, A Comparative Study of Liability Law and Compensation Schemes in Ten Countries and the United States. Oak Brook, Ill.: Insurance Research Council, 1991. 


\subsection{The cases}

Although a certain amount of general background information was indispensable for understanding the rules and procedures of each country, the central part of the study was the discussion of the cases and the calculation of the amounts payable under different rules from different sources for different kinds of loss. Great care was therefore devoted to the selection and description of the cases to be used.

Evaluation of the preliminary stage showed that the study could not be based exclusively on published court decisions handed down in actual cases, as in most countries except perhaps the United Kingdom, the number of published cases was too small to yield the sample of sufficiently similar situations that was needed for comparable analyses.

Instead, a number of accident/injury situations were constructed as hypothetical cases, providing as much detail as appeared necessary to assure comparability and to serve as a basis for computing benefits and compensation.

Care was taken to include slight and moderate as well as severe injuries, as well as different types of accidents and victims, selected so as to provide an opportunity for demonstrating the different national approaches with respect to legal rules of liability, compensable damages, and alternative benefits.

Eventually, our set of cases was composed of six accident situations, with two or three standard victim/injury situations each, resulting in a total of 15 cases.

Following is a summary of the cases. In the Research Plan, reproduced in the book, the accident situations and the victims and their injuries were described in more detail to provide a common base for calculations.

\section{Accident situation $A-$}

Vehicle collision, caused by driver's fault, resulting in injuries to passenger, who had not fastened seat belt.

Case $1 \mathrm{~A}$

Divorced woman killed, leaving 6-years old daughter.

Case $2 A$

17 year-old schoolgirl slightly injured (broken leg).

Accident situation $B$

Pedestrian hit by car on crosswalk.

Case $3 B$

8 year-old boy slightly injured (broken leg).

Case $4 \mathrm{~B}$

75 year-old woman killed.

Case $5 \mathrm{~B}$

24 year-old single medical student killed.

Accident situation $C$

Work accident (interference with stamping machine)

Case $6 \mathrm{C}$

Foreman killed, leaving wife and 2 children of school age. 
Case $7 \mathrm{C}$

22-year old single unskilled laborer (illegal immigrant) blinded.

Accident situation $D-$

Work accident, same facts as $\mathrm{C}$, plus facts suggesting gross negligence.

Case $8 \mathrm{D}$

Same facts as in $6 \mathrm{C}$.

Case $9 \mathrm{D}$

Same facts as in $7 \mathrm{C}$.

Accident situation E-

Injury caused by defective product, due to producer's negligence.

Case $10 \mathrm{E}$

47-year old self-employed lawyer temporarily blinded.

Case $11 \mathrm{E}$

38-year old housewife temporarily blinded.

Accident situation $F-$

Environmental contamination (chemicals in water supply), causing subjective discomfort, temporary relocation.

Case $12 \mathrm{~F}$

Several members of family claim damages for discomfort, fear of developing cancer, reduced life expectancy, miscarriage, genetic damage.

County claims cost of decontaminating the groundwater and the cost of temporary relocation.

Accident situation $G-$

Medical treatment injury (penicillin allergy after physician's failure to inquire about disposition).

Case $13 G$

55-year old housewife, 1 extra week in hospital.

Case $14 \mathrm{G}$

47-year old self-employed lawyer, 1 extra week in hospital.

Case $15 \mathrm{G}$

42-year old foreman, 1 extra week in hospital.

\section{Summary of the results}

This summary is limited to a subjective selection of issues and neither will nor can be a substitute for studying each of the national reports. Indeed, the national reports contain such a wealth of information both on the basic structure of the respective systems and on the standards and procedures used for calculating compensation in individual cases, that to analyze them satisfactorily would require another volume.

For the reasons indicated in the Introduction, direct comparison of the results obtained for each of the 15 cases in the six countries would not be a meaningful exercise. For the same reasons, no attempt was made to tabulate the results. Such tables would only suggest a degree of comparability that simply does not exist. 


\subsection{Basic structural differences}

Comparisons of accident compensation in the United States and Europe (and other countries) commonly point out as a principal difference that a large portion of the cost which in the United States has to be processed through the liability system is in Europe covered by social security.

Before examining to what extent this statement is confirmed by our study, it must be stressed that we are looking for differences of degree rather than principle. Actually, American accident victims do receive a substantial portion of their compensation in the form of benefits from various private or public insurance schemes. Liability is neither the exclusive source of compensation nor does it provide compensation for every accident.

Thus, the Institute for Civil Justice found, in a recently published study, that only $10 \%$ of the accident victims surveyed received any compensation through a liability claim, and that the total indemnities received accounted for $7 \%$ of the total compensation received by all victims surveyed. ${ }^{7}$ The same study found that between 60 and $67 \%$ of the victims received insurance benefits for their medical expenses, and $40 \%$ received benefits for loss of income during short-term disability. ${ }^{8}$ There were (as might be expected) considerable differences by type of accident (work, automobile, other).

\subsection{Social security systems}

In the countries represented in this study, social security is designed to provide comprehensive protection against the elementary contingencies of life for all, or at least for all who cannot be relied on to provide for themselves. While this basic goal is shared by all, the details of the national systems show a confusing variety, which nevertheless is easily explained: much more than the rules of tort law, the rules of social security are instruments of redistribution, and consequently are much more sensitive to shifting perceptions of social needs, economic conditions, and prevailing political philosophies.

For comparison with the United States, the most important finding is the almost universal coverage of health care through government schemes. In all countries except Germany and the Netherlands, the automatic or compulsory health coverage applies even to selfemployed persons such as lawyers.

Coverage tends to be comprehensive. In many countries, patients are not billed individually for the services provided, and thus do not know the cost. It was this practice that produced the misconception of medical care being "free", and caused it to be disregarded in most studies of accident costs. For the present study, it was essential to include the cost of medical care, but to quantify that cost proved to be very difficult.

Social security administrators, employers and politicians have always known that health care is not free. Indeed, its cost has risen at alarming rates everywhere. Several reports tell of efforts to economize, including modest contributions by patients designed to make them at least aware of the cost and to encourage reasonableness in claiming benefits. It is especially noteworthy that such tendencies are reported even from Sweden.

${ }^{7}$ D. R. Hensler et al., Compensation for Accidental Injuries in the United States, Report No. R-3999-HHS/ICJ, Santa Monica, Cal.: Rand, 1991, at p. 107.

8 Id. at pp. 75 and 88 . 
With respect to work accidents, the diversity is even greater than for health care generally.

The work accident systems of many countries, including Belgium, France, and Germany, reflect the same basic compromise as the workers' compensation systems of most states of the USA - they provide guaranteed benefits for all work-related accidents (as well as occupational diseases), irrespective of the employer's or the worker's fault, at levels more generous than those of health insurance schemes, and preclude tort liability claims against the employer, notably for pain and suffering. These schemes, unlike workers' compensation insurance in the USA, are organized as separate divisions within the social security system.

However, as this study shows, this pattern is far from universal. In the Netherlands and in the UK, social security benefits are the same for all disabilities whether caused by work or non-work accident or by sickness, and they are not exclusive - they do not preclude the employer's liability under general law. Indeed, liability in these countries appears to be quite strict, and may include substantial amounts for noneconomic loss. Employers in the UK are required to carry (private) liability insurance.

In Sweden, social security does provide special disability benefits in case of work injuries, without affecting the employer's direct liability. On this basis, a private insurance scheme (the Security Insurance) now provides benefits determined by the rules of tort law (including pain and suffering).

\subsection{First-party benefits at tort-law standards}

The Swedish work accident insurance scheme is part of what has become known as "the Swedish approach" - a melding of no-fault entitlement and fault-based indemnification that has no equal even in Europe. As Carl Oldertz explains in his report, similar schemes have been established for traffic accidents (this one compulsory), for injuries caused by medical treatment or by pharmaceutical drugs, and most recently for damage caused by environmental pollution. In all of these schemes, the premiums for the insurance, and thus the costs of compensation, are borne entirely by those who would potentially be subject to liability.

For an American, this must surely look like a combination of two evils, and he is bound to wonder how such a scheme can possibly survive financially. The secret is in the standards and procedures for determining compensation for noneconomic loss: There are no juries deciding on awards with no knowledge of precedents and with minimal guidance and review; indeed, there is hardly any litigation at all. Instead, the awards are set in accordance with elaborate guidelines, on the basis of the opinion of independent medical experts, in such a way that even mild discomfort is recognized with a modest sum while compensation for the most severe suffering still stays within the limits of reasonability.

The Swedish approach is one of the most impressive examples of an approach which, although evidently working successfully in one country, appears to be difficult to export on a large scale. Belgium contemplates adoption of the patient insurance, as do other countries. For Germany, it was considered but found unsuitable. Among other things, it requires a measure of restraint and a commitment to reasonability that do not exist in other countries. Further, it requires a relatively small, coherent and disciplined insurance market, which also is not to be found in most other countries. 
In the light of the Swedish model, it is most fascinating to note the successful marketing in France and Belgium of a voluntary automobile accident insurance providing benefits defined in terms of tort indemnity rather than the conventional fixed amounts. As Simon Fredericq points out in his report, this coverage can be offered at a very low price because it is strictly supplemental - the defined benefits are payable only to the extent that the loss is covered neither by social security benefits nor by indemnification paid by a responsible third person.

American readers may note a superficial similarity to the uninsured and underinsured motorist coverages common (and in many states required by law) in the United States. In fact, however, the coverages are fundamentally different: American UM coverages are designed for liability claims that cannot be enforced for lack of insurance. To recover, a claimant must prove to his own insurer the facts that establish the uninsured driver's liability. This situation is not contemplated at all by the Belgian policy. In Belgium, like in most other European countries, compensation in the rare cases where there is no liability insurance is provided by a compensation fund. Rather, the Belgian policy pays where an American UM coverage would not apply - accidents for which no third party, insured or uninsured, can be blamed.

While the Swedish approach is unique in measuring first-party benefits by tort law standards, the use of private group insurance schemes to supplement social security benefits for employees is quite common in all countries.

\subsection{Liability rules}

Liability rules were not as such a subject of this study, and were referred to only indirectly as one among several potential sources of compensation, and as one of the areas of continuing evolution.

It deserves to be noted, nevertheless, that the concept of strict liability continues to expand, with the European Communities' uniform rules of products liability the principal example. Another example is the French motor vehicle liability legislation, which also had an impact on Belgian law. The trend toward strict liability is also strong in Germany and the Netherlands, notably in matters concerning the environment.

Worth noting are the different consequences attached by the law to the injured person's own negligence. The general rule in most countries and for most types of liability is that there is a strict inverse relationship between the degree to which the injured person's negligence contributed to the injury and the degree to which he may be indemnified.

The rule does not apply in Sweden, where only intent or (in case of injury) gross negligence may justify a reduction. In France and Belgium (and according to the most recent decisions of the Supreme Court, also in the Netherlands), non-motorized auto accident victims have their claims reduced only in case of wilful misconduct or "inexcusable fault", or, in France, if they are very old or very young, not at all.

The rule is applied to employer's liability in the UK (with the result that in Case 8 $\mathrm{C}$ in this study the injured foreman is limited to social security benefits), while in the Netherlands a worker would have to cause an injury intentionally to lose his claim. 


\subsection{Compensable damages}

\subsubsection{Principle of indemnity}

All countries recognize the principle of indemnity as the basis on which to determine compensable damages. The injured person is to be put in a position as close as possible, economically, to that in which he would be, had the accident not occurred. He is supposed to be neither worse off, nor better. Among other things, this principle is the basis of the rules regarding deduction of compensation received from other sources (these rules are discussed more thoroughly below, at 3.7.).

In practice, as the national reports show, the indemnity principle is applied in quite different ways and degrees in the different countries. Strict application may involve rather complicated calculations and estimates, especially for taking into account tax savings, or for evaluating the loss caused by the disability of a housewife.

Long-range loss of income due to disability poses special problems. Neither the victim's actual economic situation nor his hypothetical development without the accident can be predicted with anything approaching desirable reliability. The logic of the indemnity principle would require re-evaluation at regular intervals for as long as the effects of the accident last. Yet our legal systems and public policies require certainty and definitive decisions.

The reports in this study reflect different compromises between the conflicting goals. Because the problem is not limited to loss of income, it will be discussed later (at 3.6.).

Some reports recognize that overcompensation may result from the prevailing method of basing disability compensation, both under social security and tort law, strictly on the degree of physiological impairment as ascertained by a medical expert rather than on actual occupational activity and earning potential. In Sweden, benefits for partial disability are perceived, in part, as a reward or incentive for returning to work.

\subsubsection{Compensation in case of death}

Another challenge to the principle of indemnity is posed by cases where the accident has caused the death of the victim and has thereby eliminated the holder of the original right to compensation. After the victim's death, the principle of indemnity must be applied to persons who were not themselves personally injured.

The victim's life as such is not amenable to valuation in strictly economic terms. While it might be possible with appropriate (and usually overoptimistic) assumptions to estimate the expected life-time earnings of a young active person, application of economic standards to a person past retirement age might easily result in negative figures. In most countries, therefore, placing an economic value on human life is rejected as offensive to still prevailing notions of humanity and decency.

What remains are indirect losses suffered by survivors, primarily in the form of funeral expenses and loss support.

Taking the indemnity principle to its logical consequences, Belgian practice will not recognize funeral expenses as compensable it they are claimed by someone (e.g., presumably, the victim's estate) who in the normal course of events would have had to pay them anyway eventually. None of the other countries apparently goes that far. 
In an exception of a different kind, Dutch practice reduces a survivor's claim for loss of support by the interest earned on moneys received as an inheritance or from a life insurance. In the other countries, such amounts are commonly disregarded, although strict application of the indemnity principle supports the Dutch practice.

If death benefits and widows' and orphans' pensions are taken into account, not much remains to be recovered by survivors by way of a liability claim. Dissatisfaction with the modest levels of economic compensation combined with the desire to recognize in some way the noneconomic value attached to a human life may explain the various types of additional compensation awarded to survivors in the different countries.

\subsubsection{Compensation for noneconomic loss}

The principle of indemnity recognizes only losses that can be measured in economic terms. In addition, tort law everywhere has traditionally recognized as compensable a variety of harms and detriments that cannot possibly be converted into a sum of money.

It is not at all surprising to find the greatest variations in this area - in different ways to classify, to organize, and to rate such losses, in an effort to measure and make predictable what by nature and definition defies measurement. The approaches demonstrated in this study say as much, or more, about different notions of fairness and equity, of individual and collective justice, and of the style of legal thinking, as they say about legal theory and public policy.

The diversity starts with the basic definition and the separation from economic losses. It is not identical with the traditional separation in the Common Law of the UK between "special" and "general" damages, which corresponds roughly to that between loss items that have already materialized and are amenable to precise accounting, and those expected to arise in the future, and therefore inherently speculative, including loss of income or support, or a need for special care, services, and accommodations.

The items just mentioned are still recognized as economic loss, inasmuch as they affect the economic circumstances of the injured person and are capable of being expressed in monetary terms, even though they are difficult to estimate, and are often compensated on the basis of generalized standards without regard to the injured person's actual needs. Noneconomic losses, in contrast, are consequences in the field of emotions, and by their nature incapable of measurement in monetary terms.

The different nature of economic and noneconomic losses suggests separate determination. This is indeed the rule. Compensation for noneconomic losses follows the principle of equity and requires broad room for discretion. That, however, is also true to some extent for the economic loss items included in the "general damages". Consequently, it is possible under the "point" system used in Belgium in cases of permanent disability, to award an aggregate amount for both the economic and the noneconomic loss related to this particular disability.

In most countries, compensation for noneconomic loss is determined by looking exclusively at the claimant's circumstances - his injuries, disabilities, sufferings or distress. Germany appears to be standing quite alone in including, in an overall equitable consideration of all circumstances of the case, the conduct of both parties both before and after the accident, and the economic circumstances of both parties. Thus in Germany not only 
will a poor victim be likely to recover more for pain and suffering from a rich tortfeasor than vice versa, but also an "innocent" victim is likely to recover more from someone who caused the accident by acting with exceptional recklessness.

This means that while generally punitive or exceptional damages are not recognized in the countries represented in this study, pain and suffering awards in Germany may include a punitive element - which, however, will never amount to more than a minor factor among many others determining the award.

The equitable and potentially punitive nature of pain and suffering awards is the principal reason why in Germany noneconomic loss is compensable only in cases of negligence, and not under strict liability laws. In turn, the need to prove negligence to recover damages for pain and suffering is the cause of a significant portion of tort litigation in Germany. The other countries will award damages for noneconomic loss whatever the basis of liability.

While German practice requires all applicable considerations to congeal in one undivided amount for the aggregate of noneconomic losses suffered, the other countries will award separate amounts for different types of loss, commonly distinguishing between the immediate physical pain and suffering, the continuing discomfort associated with having to live an impaired life, and the general loss of enjoyment of life. Some countries, notably France, are more specific.

France and Belgium also recognize the emotional loss suffered by persons close to the person killed in an accident. In the United Kingdom, a similar result is produced by the bereavement award under the Fatal Accidents Act.

In the other countries, noneconomic losses are conceptually linked to a personal injury, and grief alone is not recognized as a basis for a claim. Shock may under certain circumstances qualify as a personal injury, however, and there is a tendency, noted especially in the UK report, to extend the range of circumstances under which shock may justify an award.

As another consequence of the conceptual link between noneconomic loss and personal injury in some countries, the claim can be pursued only by the injured person himself and ceases to exist when that person dies, except if the claim had already been substantiated by acknowledgment or by an action in court. Germany repealed its traditional limitation in 1990, and thereby joined those countries, as Belgium, where the injured person's heirs are enriched by receiving awards for pains which they did not themselves suffer.

While in the United Kingdom, Belgium, the Netherlands and Germany awards are set individually for each case in consideration of the unique circumstances of that case, with nothing to provide guidance and to help in predicting decisions except precedents, compiled in unofficial collections of decisions, French practice relies strongly on tables assigning specific amounts to different degrees of medically certified disability or impairment.

Sweden has proceeded farthest in the development and uniform application of schedules for noneconomic loss. From Carl Oldertz' report it appears that for each case the appropriate amount of compensation can be predicted with considerable confidence on the basis of a medical evaluation of the injuries and impairments. It is worth noting that the Swedish guidelines are most specific in the lower range of severity, where the largest number of cases is to be found, and become less specific with increasing severity. In what 
amounts to a sad commentary on the reality of human suffering caused by accidents, the provisions for the most severe cases, apparently the result of successive amendments, show that no impairment, considered to constitute the ultimate suffering, is so extreme that it cannot be surpassed by something even worse.

Where compensation is awarded for functional disability, or incapacity, even very minor degrees, down to three or even one percent, are supposed to be ascertained through medical examination, and carry their specific awards. Other types of impairment or discomfort may be disregarded if they are less than "slight". In general, however, it appears that even slight discomfort and slight consequences are recognized as justifying some (modest) compensation.

\subsection{Payment modalities}

Strict application of the principle of indemnity would require compensation to match the respective loss not only in amount but also in terms of the time of incidence. With respect to future recurring losses (loss of income or support) this means payment in monthly or annual installments.

The indemnity principle not only requires annuities but it requires them to be adjusted to reflect changes both in the injured person's or claimant's condition and in the cost of living.

This is, consequently, what German law prescribes. The laws of other countries (France, Belgium, Sweden) also provide for (indexed) annuities at least at the option of the court. In the United Kingdom, in contrast, lump-sum payments are the rule.

For various pragmatic reasons, annuities are not popular with insurers nor with many claimants. Insurers, as the Belgian report reveals, will favor annuities only when they expect the beneficiary to die within an relatively short time.

Among the claimants, there are many who prefer to lay their hands on a large sum of money immediately. Here, of course, are also the dangers of lump-sum or capitalized compensation: not all claimants are able to manage the funds prudently for their longterm benefit.

In the United Kingdom, "structured settlements" have recently become more popular. Like the conventional statutory annuities of the other countries, they stretch out payment over an extended period of time. For the claimant, they are an attractive alternative to the traditional lump-sum payments because under the tax rules of the UK they allow him to receive investment income free of taxes, which would not be possible if he invested a lump sum on his own. The liability insurer can still close its account with a one-time payment. An impressive illustration was provided in Appendix 3 of the preliminary report for the UK (No. 56 of the Geneva Papers, at p. 271).

Structured settlements work to the fullest advantage of all concerned if things go as planned; while they may include a provision for regular increases, there is no way to adjust the benefits if the cost of living or the recipient's personal condition takes an unexpected turn.

Taxation usually depends on whether a payment constitutes indemnification for lost income. In those instances, taxes must be taken into account in calculating the amount payable. 
Delays caused such concern in France that the law of 1985 provides penalties for insurers that do not make a settlement offer within the deadlines prescribed. In the other countries, the problem of delay, to the extent that it is recognized, apparently is not one of serious proportions.

It must be kept in mind that an injured person's immediate needs are practically without exception taken care of by social security, without a need to advance money or to wait for a settlement offer by the liability insurer.

Several reports point out, on the other hand, that certain delays are unavoidable, especially where the injured person's condition must be allowed to stabilize before the existence and extent of a permanent disability can be determined.

For France and Belgium, intercompany agreements providing for settlement by the injured person's own insurer are cited as a means to expedite payment.

Interim payments, of amounts that can be determined separately and definitively, appear to be common.

\subsection{Coordination}

In the countries represented in this study, accident victims and their dependents and survivors are not allowed to be compensated twice. Rather, as noted, the indemnity principle requires compensation from other sources to be taken into account, to a greater or smaller extent, when determining liability claims.

The most common criterium for distinguishing deductible and nondeductible benefits is whether they are designed as an indemnity to cover the same loss. Under this test, sometimes (e.g., in Germany) referred to as the test of congruence, social or private insurance benefits defined in terms of specific medical costs or loss of income are usually deductible, while lump-sum benefits paid under a life or accident policy are not. As the national reports show, there are many exceptions to this rule. The Netherlands seem to apply a broader definition of deductible advantages, while the traditional practice in the United Kingdom is much more restrictive.

In most countries, the law will not let the deductions work to the benefit of the responsible party but rather provides for recourse, or subrogation, for the provider of the other benefits.

Subrogation is based on the public policy against unjust enrichment, which is also the basis of the principle of indemnity. Social and private health and accident insurance schemes are designed exclusively for the benefit of the injured person, and are financed by the injured person, or by others or the community, in his behalf. It is not their purpose to benefit the person who caused the accident through wrongful or dangerous conduct. This policy can also be expressed in terms of economic theory as avoiding the externalization of social costs.

Subrogation appears to be most firmly established in the practice of Belgium, France, Germany and the Netherlands. In contrast, it is not used at all in Sweden, and only to a limited extent in the United Kingdom. In a noteworthy modification, the Netherlands preclude subrogation in the newly created cases of strict liability, thus limiting the liability to those losses that are not covered by other benefits.

Sweden apparently dispensed with subrogation primarily for pragmatic considerations relating to the relative costs and benefits of what in effect would amount to a shifting of 
costs among collectives (those contributing to social security and those contributing to motor vehicle liability insurance) that were to a large extent identical.

In the United Kingdom, subrogation has had a particularly complex history, with a most fascinating last chapter, which produced "the clawback". The clawback, its evolution and its limitations and inherent problems are described in detail in the preliminary and final reports for the UK, and no attempt will be made here to analyze it. Time will have to show how it works and what its effects will be. The five-year limit substantially limits the amounts that may be recovered, and this may keep the beneficiaries (social security carriers) from committing the resources and efforts that would be necessary to develop the remedy to its full potential.

Special note is due the National Health Service's right to recover costs up to specified limits from a motor insurer, with the only requirement being that the insurer made payments to the patient on account of the accident. While this does not conform to the common concept of subrogation, it does serve the same purpose.

The figures provided in the preliminary report for Germany show that subrogation is not an insignificant factor. This is confirmed with great emphasis, though without reference to specific figures, by Simon Fredericq for Belgium.

Simon Fredericq also points out that subrogation involves additional costs. The desire to minimize costs and maximize efficiency appears to be the principal moving force behind the loss sharing agreements between German liability insurers and social security carriers, providing for payment of standard percentages without examination of the issue of fault.

Subrogation on an individual, case-by-case basis is not the only way to shift, or reallocate, accident costs. Belgian automobile owners are required by law to pay a special contribution, defined as a percentage of the liability insurance premium, to social health insurance. This is in effect an instance of collective cost shifting: It shifts to automobile owners collectively a part of that portion of the cost of treating automobile accident victims that cannot be recovered through subrogation (e.g. because no third party was responsible for the accident).

A similar provision (not mentioned in the French report) exists in France (code des assurances, art. L. 213-1). There the rate of the contribution is now at $15 \%$ of the liability premium.

Coordination and the prevention of duplication is also a problem among benefits from several parts of the social security system. Disability or survivor pensions under work accident insurance often coincide with pensions paid under the general old-age and disability pension laws. Some of the national reports mention provisions limiting the total to be paid in such case to the larger of either of the single pensions, or to a specified amount. Even there, some instances of overcompensation remain.

Overcompensation may also result from accumulation of standard social security benefits and benefits provided by supplementary group insurance schemes owing their existence to labor-management agreements.

\subsection{Procedures and cost}

In these two respects, the information provided by the national reports is not as extensive and specific as an American reader might wish. European insurers do not normally collect information on settlement costs separately for personal injury claims. 
While the two reports for the UK provide extensive information on the civil justice system, including recent changes and the review currently under way, the other reports devote much less attention to this aspect. Generally, litigation appears to be rare, with the exception in some countries of motor vehicle accidents.

As pointed out in the German preliminary report, the extensive coverage of medical costs and loss of income under social security usually leaves only damages for noneconomic loss as a subject of an individual claim and potential lawsuit (apart from property damage).

Consequently, the costs and delays that are inevitably associated with litigation, regrettable as they may be, in the majority of the cases do not keep the injured person from receiving necessary medical care and do not cause financial hardship.

Both litigation behavior and litigation costs are in some countries (notably Belgium, France and Germany) strongly influenced by the prevalence of legal protection insurance coverage ${ }^{9}$ as well as by intercompany loss settlement agreements under which claims are regularly settled by the injured person's own insurer.

In evaluating the costs of litigation, it must also be considered that all the countries in this study adhere to the rule that the "costs follow the event", and that therefore a successful claimant will be able recover all or at least a considerable portion of his expenses from the losing party. ${ }^{10}$

Costs that are shifted to the liability insurer do not disappear but remain part of the total costs of the system, of course. What needs to be emphasized, however, is that in contrast to a successful American claimant, who may have a contingent fee of $30 \%$ and other expenses deducted from his award, a European claimant hardly ever bears any of the costs, whether he prevails or loses. In the former case, the liability insurer pays, and in the latter case, the legal protection insurer.

\subsection{Cost allocation}

One of the objectives of the project was to show how the economic cost of accidents is allocated. To this end, some national reports include summaries indicating which amounts are eventually borne by social security, by liability insurers, and by the victim himself.

We are aware that our approach is a rather crude one and does not come close to satisfying the methodological requirements of rigorous economic analysis. We do not even attempt to define what we mean by "economic costs"; we do not claim to have taken account of all the items that should properly be included; for instance, we do not consider the contributions to social health insurance paid by Belgian and French automobile owners as a percentage of their liability premium; and we do not evaluate the fact that the cost of social security and liability insurance is in turn spread among policyholders, employers, employees, and taxpayers.

We believe, however, that the information about cost allocation, limited as it is, still serves a useful purpose in the context of this study, by giving readers, especially those

${ }^{9}$ For details, see W. Pfennigstorf, The European Experience in Legal Expense Insurance, in W. Pfennigstorf and S.L. Kimball, Eds., Legal Service Plans: Approaches to Regulation (Chicago: American Bar Foundation, 1977) pp. 487-565.

${ }^{10}$ For details, see W. Pfennigstorf, The European Experience with Attorney Fee Shifting, in 47 Law and Contemporary Problems 37-83 (1984). 
from the United States, a rough impression of the share of the total burden carried by, or channelled through, the different parts of the compensation system in each country. Our figures are made more meaningful than those heretofore available by including the cost of health care provided through government schemes, even if only in the form of average figures.

\section{Observations regarding the model cases}

What follows is not an exhaustive analysis but rather an overview of the information supplied in the national reports.

One of the most fascinating aspects of this study is the difference of attitudes reflected in the way in which the reports discuss the accidents, the injuries, and the other circumstances of each case - differences in respects such as dedication to detail, or a special effort to understand the plight of the victim. The differences may be more imagined than real. To some extent, they may be explained by differences of personal writing style of the individual reporters, or the reporters' own occupational experience.

In any event, these differences provide ample material for contemplation and speculation over possible distinguishing elements which do not appear on the surface of the reports.

\subsection{Case $1 \mathrm{~A}$}

The case of the mother killed in a car collision, leaving a young daughter orphaned, demonstrates the full range of survivor compensation under social security and liability. In some countries it would make a difference whether the victim was on her way to or from work, because then work accident rules would apply, resulting in more generous benefits.

The reports are most impressive in demonstrating the variety of factors that are taken into account in determining both social security benefits and liability claims for loss of support.

Equally impressive are the differences in the amounts recoverable for noneconomic loss, ranging from nil in Sweden to sizeable amounts for bereavement in Belgium, France and the UK.

Likewise, the effect of the victim's own negligence varies over a wide range.

\subsection{Cases $2 A$ and $3 B$}

Predictably, the relatively slight injuries suffered by young people of school age result in less extensive claims. There are, however, noteworthy differences in evaluating their noneconomic loss.

\subsection{Cases $4 B$ and $5 B$}

These two cases involving victims killed with no dependent survivors demonstrate the absence in most jurisdictions of a direct independent value placed on human life. Noneconomic loss is limited to funeral expenses (in Belgium it may not even include those) and whatever expenses were incurred for emergency medical care. Compensation for the survivors' bereavement are available only in France, Belgium and the UK. The victim's own claim for pain and suffering passes to the estate in Belgium and Germany. 


\subsection{Cases $6 C-9 C$}

The four work accident cases demonstrate, first, the generally large extent of the benefits available to work accident victims under the social security systems, without regard to the victim's own fault. Second, they show the considerable practical effects of the rules concerning the employer's liability for fault. In Belgium, France and Germany, the injured worker is limited to the benefits provided by the accident insurance system; in the other countries he is in addition entitled to compensation for noneconomic loss, which in case of blindness may be a sizeable amount.

The injured person's own fault in Cases 8 and 9 is irrelevant everywhere except in the UK, where it may reduce or completely preclude any indemnification under employer's liability.

The employer's unconscionable conduct suggested in Cases 7 and 9, in hiring an illegal alien and placing him, apparently without proper training or supervision, before a dangerous machine, is irrelevant in the Netherlands and in the UK, where the employer is already liable for a lower degree of fault; in France it will entitle the injured worker to indemnification under tort law, including noneconomic loss, despite the general preclusion. In Germany it will result only in an internal recourse by the work accident mutual, without affecting the injured worker's rights. Under the Swedish Security Insurance, the employer's fault is as irrelevant as the worker's.

\subsection{Cases $10 \mathrm{E}$ and $11 \mathrm{E}$}

These cases show, as expected, that liability for injury caused by defective products is recognized everywhere, though under different theories. The issue of strict liability or presumed fault did not arise.

The cases were designed to bring out differences in the treatment of self-employed professionals by the respective social security systems, and indeed they do. They also demonstrate the difficulties of determining the compensable loss of income of a selfemployed person, and the efforts undertaken in the different countries to arrive at a reasonable estimate, both for these losses and for the loss resulting from the disability of a housewife.

It is particularly worth noting how the type of practice of a lawyer determines not only his income level but also the extent of the loss in case of disability. Solo practitioners (in the UK, notably barristers) face greater risks than those in partnerships.

\subsection{Case $12 \mathrm{~F}$}

This case departs from the general pattern in several respects: it represents an area of the law which is still in an early stage of development, and it includes claims for other than personal injuries. It was designed as a challenge to show how the different systems deal with new types of claims, and the facts provided were deliberately left sparse and vague.

This and the absence of suitable precedents may explain why some national reports found little to say about this case. The most extensive discussions are to be found in the British and German reports, which could rely on convenient precedents. Most of the reports agreed that relocation was not a necessary measure to take under the circumstances 
as described, and the cost therefore should not bc fully recoverablc. The majority also was reluctant to award damages for the discomfort and fears complained of.

\subsection{Cases $13 G-15 G$}

The three medical malpractice cases produced little diversity and little new information with respect to liability or benefits. Somewhat surprisingly, only some of the reports considered that under the circumstances the hospital would itself absorb the cost of the necessary additional care and treatment.

\section{Conclusions}

To the extent that it is possible to sum up a summary of six reports, the following observations seem in order:

5.1. European compensation systems are anything but uniform either with respect to underlying rules or with respect to results. All of them rely on a combination of social security, voluntary (especially cmployer-sponsored) insurance schemes, and tort liability. The roles and weights assigned to the different parts, and the results in individual cases, depend on nationally different evaluations of social needs, compensable losses, and the relevance of negligence.

Social security satisfies the immediate basic needs for medical care and continued income or support. In some countries, medical benefits apply universally, even to selfemployed persons; elsewhere, and with respect to lost income, self-employed persons are left to provide for their own needs, often resulting in more modest compensation. For employees, loss of income benefits range between $75 \%$ and $100 \%$, depending on the intricacies of the social security system and the existence of supplementary schemes.

5.2. Tort law has preserved an important role as a source of compensation for economic loss not covered by social security and for noneconomic losses. In some countries it also serves to shift part of the cost of basic benefits from the social security system to those on whom the law places responsibility for the accident. It is here where the greatest differences are found.

Tort liability is completely replaced by social security benefits only in the special case of work accidents, and only in three countries.

5.3. Even the unique "Swedish approach" has not abolished tort law but rather has adopted the central element of tort liability - full indemnification including compensation for noneconomic loss - as part of several no-fault insurance schemes.

It could be argued - and defenders of the traditional notions held by American trial lawyers will no doubt so argue - that by becoming part of a no-fault scheme the remedies of tort law will be transformed into standardized benefits like those of social security and cease to be the "full indemnification" which in the traditions of tort law is to be determined individually on the basis of the unique circumstances of each case. The elaborate schedules appended to the Swedish report could be cited as proof of that already happening.

The answer depends on personal attitudes and preferences and on national traditions and policies and therefore is bound to be different in each country. The Swedish public evidently accepts the compensation provided by the various schemes as full compensation. 
5.4. A common element of the six systems represented in this study is the commitment, based on the principle of indemnity, to coordinating the two types of sources to the end that no one should receive in the aggregate more than the amount of the actual loss suffered. An equally strong policy in the majority of the countries will not let the person who is responsible for an accident derive an advantage from social security and other benefits provided to the injured person.

Differences among the countries reflect the continuing search for an acceptable compromise between the conflicting goals of any compensation system: equitable consideration of the unique circumstances of each individual case, predictability of results, and maximum administrative efficiency and economy.

As pointed out earlier, the need for compromise is compounded where losses and needs cannot be measured by economic standards but are largely or exclusively a matter of equity or compassion. Whatever classifications, reference points, scales and guidelines evolve, by precedent, usage, convention or official pronouncement, to aid in making and predicting decisions - they cannot, by the nature of the matter, determine what is "right".

5.5. The conclusion that is most forcefully supported by the national reports is that there is no single "right" set of rules, procedures and standards for compensating accidental injuries. The reports teach us that the conflicting goals for any compensation system can be approached, even within the same country, in a variety of ways, all of which are "right". All of them are compromises that have evolved over a long period of time and have become established in the respective countries, with a body of precedents and usages that in practice allows most cases to be settled routinely without controversy.

5.6. An incidental conclusion is that it would be not only extremely difficult but also of questionable merit to try to make rules and standards uniform. It is true that comparison with other jurisdictions is one way in which legal systems evolve, and in this context it is particularly worth noting how the Amsterdam Appeals Court relied on a comparative study of awards in EC member countries to justify a larger award than would result from an application of Dutch precedents. Another foreign influence cited in several reports is the "North American factor".

On the other hand, the reports tell of different standards and even different methods of determining compensation among the jurisdictions of different courts of appeal within the same country. Obviously, preservation of the possibility of subjective evaluation of the equity of the individual case is considered more important than uniformity. Even in Sweden, different guidelines apply to different types of injury.

5.7. While there are no major complaints, the different national compensation systems keep evolving. Generally, it appears that social security, after several decades of vigorous expansion, has reached a stage where the public resists further increases of the financial burden and therefore efforts are made to limit costs, notably by having patients assume some of the costs of health care and thus discouraging excessive utilization.

Tort law, despite the availability of generous social security benefits, shows no sign of withering away but rather is under continued pressure to expand everywhere, with the possible exception of Sweden (where tort standards continue to dominate no-fault insurance schemes). 
The expansion, which takes the form of increasingly strict duties of care, new types of strict liability, recognition of new kinds of compensable damages, and especially rising awards for noneconomic loss, has caused some concern in some countries but has not reached crisis proportions or demands for reform comparable to those in the United States.

Proposals (e.g., in Belgium and in the UK) to replace medical malpractice liability with a compensation scheme following the Swedish model appear as exceptions and a response primarily to the special situation of health care and its cost.

The pressure for expansion of tort liability and for larger awards may in part be explained as an effect of misleading and exaggerated reports about compensation awards in the United States. To a considerable extent it appears to be home-grown, however a by-product of rising standards of living, even faster-rising expectations, and strong consumer movements in Europe.

One of the national reporters, speaking at a public discussion we had on this project in London, in October 1991, characterized the trend more bluntly as being driven by greed. The author of this Summary, on the basis of what he knows about the situation in Germany, has to agree that this is at least one among several factors accounting for the increase.

What worries us is not so much that greed exists as a motivating force (it always has) but that it appears to be increasingly accepted as a legitimate one. It is not an accidental coincidence that at the same time we observe a growing tolerance toward fraud, especially in regard of compensation and insurance.

Although the increase of the costs of compensation has not reached the level of a crisis, it is a cause of concern. This is, as mentioned, an area where sentiments, compassion, and greed often overrule reason. By our study, we hope to have strengthened the position of reason.

\section{NOTA BENE}

The paper on "Quo Vadis? For General Insurance Industry in Developing Countries" by R. D. Samarth, published in the "Geneva Papers" No. 63/ April 1992 was prepared on the occasion of the Third World Insurance Congress held at New Delhi, but was not presented at the Conference as one of the official papers. 